DOI: $10.17516 / 1997-1370-0867$

УДК $332.143,332.144$

\title{
Transition to the Concept of «Smart City» in the Regions of the Southern Federal District: a Correlation Matrix of Indicators of a Smart and Sustainable City
}

\author{
Olga E. Akimova, Sergey K. Volkov \\ and Alexey B. Simonov* \\ Volgograd State Technical University \\ Volgograd, Russian Federation
}

Received 05.08.2021, received in revised form 30.10.2021, accepted 10.11.2021

\begin{abstract}
A «smart city» is based on the indicators of a traditional «sustainable city», however, due to innovative development, it expands the elementary composition and complexity of system connections in a «sustainable city», updating, improving and gradually replacing it. In this regard, within the framework of this study, an attempt was made to identify indicators that can describe a «smart city», to determine the relationship of these indicators with each other, as well as to build a correlation matrix of links between indicators of a smart and sustainable city. The study was carried out using correlationregression analysis using a linear correlation coefficient. The simulation results are presented for the regions of the Southern Federal District of the Russian Federation and allow us to draw conclusions about the use of the identified relationships in the management of the development of these regions. To determine the level of entry of a particular region into the digital space, indicators were identified that act as control nodes that allow you to manage the process of transition to the «smart» category and regulate the pace of the transition process itself. A comparative analysis of correlation matrices revealed a tendency towards a weakening of the dependence of the indicators of a «smart city» on indicators of a «sustainable city», which indicates a gradual transition of a territorial entity to the concept of a "smart city» and a gradual penetration of the results of scientific and technological progress and high technologies into various spheres of human life.
\end{abstract}

Keywords: smart city, smart sustainable city, correlation matrix, digitalization, control nodes, cognitive map, correlation-regression analysis, Southern Federal District.

The reported study was funded by Russian Foundation for Basic Research, project № 19-010-00018 «Formation of adaptive methodology of regional development in the conditions of transition to the concept of «smart city».

\footnotetext{
(C) Siberian Federal University. All rights reserved

* Corresponding author E-mail address: akimovann25@mail.ru; ambiente2@rambler.ru ORCID: 0000-0001-6967-7608 (Akimova); 0000-0002-4852-145X (Volkov); 0000-0002-6771-8995 (Simonov)
} 
Research area: economics.

Citation: Akimova, O.E., Volkov, S.K., Simonov, A.V. (2021). Transition to the concept of «Smart City» in the regions of the Southern Federal District: a correlation matrix of indicators of a smart and sustainable city. J. Sib. Fed. Univ. Humanit. soc. sci., 14(12), 1885-1897. DOI: 10.17516/1997-13700867

\title{
Переход к концепции «умный город» в регионах ЮФО: корреляционная матрица показателей умного и устойчивого города
}

\section{О.Е.Акимова, С.К. Волков, А.Б. Симонов}

Волгоградский государственный технический университет

Российская Федерачия, Волгоград

\begin{abstract}
Аннотация. «Умный город» базируется напоказателях традиционного «устойчивого города», однако за счет инновационного развития расширяет элементарный состав и сложность системных связей в «устойчивом городе», обновляя, улучшая и постепенно замещая его. В этой связи в рамках настоящего исследования была предпринята попытка выявить показатели, которыми можно описать «умный город», определить взаимосвязь этих показателей между собой, а также построить корреляционную матрицу связей между показателями умного и устойчивого города. Исследование проводилось с помощью корреляционно-регрессионного анализа с применением линейного коэффициента корреляции. Результаты моделирования представлены для регионов Южного федерального округа Российской Федерации и позволяют сделать выводы об использовании выявленных взаимосвязей в рамках управления развитием этих регионов. Для определения уровня вхождения того или иного региона в цифровое пространство были выявлены показатели, выступающие в качестве контрольных узлов, позволяющих управлять процессом перехода к категории «умный» и регулировать темпы самого процесса перехода. Сравнительный анализ корреляционных матриц выявил тенденцию к ослаблению зависимости показателей «умного города» от показателей «устойчивого города», что свидетельствует о постепенном переходе территориального образования к концепции «умный город» и постепенного проникновения результатов НТП и наукоемких технологий в различные сферы жизнедеятельности людей.
\end{abstract}

Ключевые слова: умный город, умный устойчивый город, корреляционная матрица, цифровизация, контрольные узлы, когнитивная карта, корреляционнорегрессионный анализ, Южный федеральный округ.

Исследование выполнено при финансовой поддержке РФФИ, проект № 19-01000018 «Формирование адаптивной методологии регионального развития в условиях перехода к концепции «умный город».

Научная специальность: 08.00.00 - экономические науки. 


\section{Введение}

В современных условиях одним из важных факторов развития регионов и муниципальных образований является интенсивное внедрение результатов научно-технического прогресса во все сферы жизнедеятельности человека. В последнее десятилетие ведется активная научная дискуссия о том, как решения «умного города» могут обеспечить прогресс в направлении сбалансированной устойчивости, что привело к появлению новой концепции «Умный устойчивый город» (Huovilaa, Boschb, Airaksinenc, 2019).

В предыдущей нашей статье «Концепция «умный устойчивый город»: система показателей для оценки уровня региональной устойчивости и адаптивности регионального развития» была озвучена научная дискуссия относительно трактовки термина «умный устойчивый город» (Акимова, Волков, Кузлаева, 2020). Несмотря на некоторое различие во взглядах, большинство ученых признают информационнокоммуникационные технологии (ИКТ) движущей силой экологического, социального и экономического развития, направленного на решение проблем городской устойчивости. В 2013 году была создана оперативная группа МСЭ-Т по умным устойчивым городам, предложившая универсальную трактовку термина «умный устойчивый город» (Новиков, 2016). «Умный устойчивый город - это инновационный город, использующий информационнокоммуникационные технологии (ИКТ) и другие средства для повышения качества жизни, эффективности деятельности и услуг в городах, а также конкурентоспособности при обеспечении удовлетворения потребностей настоящего и будущих поколений в экономических, социальных, природоохранных, а также культурных аспектах» (Рекомендация МСЭ-Т..., 2016, с. 8).

Самые последние исследования основаны на том, чтобы подчеркнуть, что умные города обладают большим потенциалом для обеспечения городской устойчивости. Например, А. Крамерс с соавторами предполагает, что «концепция «умного устойчивого города» может быть использована в качестве способа подчеркнуть умные инициативы, направленные на содействие экологической устойчивости» (Kramers, Höjer, Lövehagen, Wangel, 2014).

Как полагают С.Е. Бибри, Дж. Крогстиб, многие исследования в области «умного города» демонстрируют различную направленность в отношении потенциала новых технологий, новых приложений и услуг, что влечет за собой передовые решения в различных областях и сферах экономической деятельности; появляется множество онлайновых и мобильных приложений, позволяющих населению повысить качество жизни, облегчить доступ к услугам в сфере образования, здравоохранения, безопасности, благосостояния, общественного участия в решении важнейших проблем и т. д. Тем не менее, несмотря на прогресс в области ИКТ, возникновение новых технологий и приложений не носит системного характера и не позволяет решать срочные насущные проблемы, например энергетическая и экологическая неэффективность, изоляция в городах, социальная несправедливость, неравенство возможностей (Bibri, Krogstieb, 2017).

Ф. Бифулко, М. Трегуа, С. Амитрано, А. Д'Аурия полагают, что роль технологий в умных городах должна заключаться в обеспечении устойчивого развития городов (Bifulco, Tregua, Amitrano, D'Auria, 2016), а не в новой технологии как самоцели. По мнению Х. Ахвенниеми, А. Уовилаа, И. Пинто-Сеппя, М. Айраксиненц, город, который не является устойчивым, на самом деле не «умный» (Ahvenniemi, Huovila, Pinto-Seppä, Airaksinen, 2017).

«Умный город» базируется на показателях традиционного «устойчивого города», однако за счет инновационного развития расширяет элементарный состав и сложность системных связей в «устойчивом городе», обновляя, улучшая и постепенно замещая его. В этой связи в рамках настоящего исследования была предпринята попытка выявить показатели, которыми можно описать «умный город», определить взаимосвязь этих показателей между со- 
бой, а также построить корреляционную матрицу связей между показателями умного и устойчивого города. Результаты моделирования представлены для регионов Южного федерального округа Российской Федерации и позволяют сделать выводы об использовании выявленных взаимосвязей в рамках управления развитием этих регионов. В рамках второго этапа исследования планируется построить когнитивную карту процесса перехода территориального образования к концепции «умный город», которую возможно будет использовать для оценки состояния конкретных регионов, сценарного прогнозирования внедрения концепции «умный город» и планирования управляющих воздействий для ускорения инновационного развития.

\section{Показатели умного}

\section{и устойчивого города}

В настоящее время доступны сотни индикаторов и несколько десятков различных индексов умных или устойчивых городов, которые уже не раз подвергались критике за отсутствие прозрачности и научных основ. Те показатели, которые предлагаются в различной научной литературе, как правило, не являются стандартизированными, комплексными и целостными, поскольку затрагивают лишь отдельные сферы или области экономической деятельности, городского хозяйства или управления. Например, В. Альбино, Ю. Берарди, Р. М. Данджелико, Л. Антопулос, М. Янссен, В. Вираккоди, У. Берарди, М. С. Старикова, Э. А. Безуглый, В.В. Шахов раскрыли собственное видение устойчивой оценки сообществ и городов с позиции креативного потенциала (Albino, Berardi, Dangelico, 2015; Anthopoulos, Janssen, Weerakkody, 2016; Berardi, 2015; Старикова, Безуглый, Шахов, 2018).

Ряд других авторов (А. Шарифи, А. Мураяма, В.Е. Рис, Д.У. Пирс, Г.Д. Аткинсон, А. Гамильтон, Г. Митчелл, С. ЮлиКарджанмаа, В. Мега, Дж. Педерсен, Л.-Й. Шен, Дж. Хорхе Очоа, М.Н. Шах, Х. Чжан, А. Акандеа, П. Кабрала, П. Гомеса, С. Кастелейнб) проводят критический анализ су- ществующих инструментов и показателей оценки устойчивости, предложенных различными учеными или являющихся основой различных европейских рейтингов умных устойчивых городов (Sharifi, Murayama, 2013; Rees, 1996; Pearce, Atkinson, 1993; Hamilton, Mitchell, Yli-Karjanmaa, 2002; Mega, Pedersen, 1998; Shen, Ochoa, Shah, Zhang, 2011; Akandea, Cabrala, Gomesa, Casteleynb, 2019).

Р. Йовович, М. Драшкович, М. Делибашич, М. Йовович, Р. Каманьи, А. В. Порохин, Е.В. Порохина изучают устойчивость как характеристику состояния региональной социально-экономической системы с позиции факторного и институционального анализа (Jovovic, Draskovic, Delibasic, Jovovic, 2017; Camagni, 1998; Порохин, 2014; Порохина, 2014). Также имеется шесть европейских стандартов умных или устойчивых городов (Рекомендация МСЭ-Т, 2016; Рекомендация МСЭ-Т, 2018; Рекомендация МСЭ-Т Y.4902/L.1602, 2018; ETSI TS103 463..., 2017), предлагающих комплексную систему городских индикаторов, анализ которых подробно был представлен в нашей предыдущей статье (Акимова, Волков, Кузлаева, 2020).

На основании анализа указанной литературы и стандартов была предложена система показателей оценки умного устойчивого города, включающая 304 индикатора, адаптированных под российские реалии и сгруппированных в семь блоков, в рамках которых выделены отдельные группы: 1) умная и устойчивая экономика; 2) население; 3) инженерная инфраструктура; 4) интеллектуальное управление; 5) социальная инфраструктура; 6) интеллектуальная мобильность; 7) цифровые платформы и данные. Однако в рамках отбора реальных показателей по Южному федеральному округу (ЮФО) для настоящего исследования оказалось, что многие показатели, которые доступны в европейских странах, в России вовсе не фиксируются статистическими органами и различными ведомствами страны (а должны бы, на наш взгляд), а часть из них фиксируется с разбивкой по другим сферам деятельности, что также 
представляет определенную проблему для их сбора и оценки. В этой связи из всего многообразия показателей была отобрана лишь небольшая часть.

Для определения уровня вхождения того или иного региона в цифровое пространство были выявлены показатели, кото- рые с достаточным уровнем достоверности отражали динамику их цифровизации или перехода в категорию «умный» (табл. 1).

Показатели, представленные в табл. 1, были выделены для оценки глубины перехода региона или муниципального образования к концепции «умный город». Данные

Таблица 1. Показатели, управление которыми позволяет оказывать влияние на эффективность перехода к концепции «умный город»

Table 1. Indicators, the management of which allows to influence the effectiveness of the transition to the «smart city» concept

\begin{tabular}{|c|c|}
\hline Показатель & Описание \\
\hline 1 & 2 \\
\hline $\begin{array}{l}\text { Число самостоятельных образо- } \\
\text { вательных организаций высше- } \\
\text { го образования, использующих } \\
\text { дистанционные образовательные } \\
\text { технологии для реализации обра- } \\
\text { зовательных программ высшего } \\
\text { образования }\end{array}$ & $\begin{array}{l}\text { Данный показатель позволяет определить уровень внедрения со- } \\
\text { временных технологий обучения, что оказывает прямое влияние } \\
\text { на применение современных технологий во всех сферах жизнеде- } \\
\text { ятельности и, соответственно, определяет уровень цифровизации } \\
\text { региона }\end{array}$ \\
\hline $\begin{array}{l}\text { Количество персональных ком- } \\
\text { пьютеров в образовательных ор- } \\
\text { ганизациях }\end{array}$ & $\begin{array}{l}\text { Обеспеченность учебных заведений персональными компьютерами } \\
\text { отражает потенциальную возможность региона внедрять и исполь- } \\
\text { зовать результаты НТП }\end{array}$ \\
\hline $\begin{array}{l}\text { Затраты на исследования и разра- } \\
\text { ботки } \\
\text { в\% к ВВП в целом по России }\end{array}$ & $\begin{array}{l}\text { Доля затрат на исследования и разработки отражает потенциал ре- } \\
\text { гиона в направлении наукоемкого развития }\end{array}$ \\
\hline $\begin{array}{l}\text { Инвестиции в объекты интеллек- } \\
\text { туальной собственности }\end{array}$ & $\begin{array}{l}\text { Финансовая составляющая является неотъемлемой частью любого } \\
\text { научно-технического развития, поскольку все исследования и раз- } \\
\text { работки требуют дорогостоящих исследований и апробаций }\end{array}$ \\
\hline $\begin{array}{l}\text { Объем инвестиций в основной } \\
\text { капитал, направленных на при- } \\
\text { обретение ИКТ }\end{array}$ & $\begin{array}{l}\text { Развитие информационно-коммуникационных технологий обеспе- } \\
\text { чивает процесс обучения нововведениям }\end{array}$ \\
\hline $\begin{array}{l}\text { Доля высокотехнологичных и на- } \\
\text { укоемких отраслей экономики } \\
\text { в ВРП }\end{array}$ & $\begin{array}{l}\text { Данный показатель позволяет оценить эффективность процесса об- } \\
\text { учения применению новых технологий, а также темпы внедрения } \\
\text { результатов НТП во все сферы экономики региона }\end{array}$ \\
\hline $\begin{array}{l}\text { Прирост высокопроизводитель- } \\
\text { ных рабочих мест }\end{array}$ & $\begin{array}{l}\text { Данный показатель позволяет отследить дальнейший переход реги- } \\
\text { она или муниципального образования к умным технологиям }\end{array}$ \\
\hline Удельный вес занятых в ИКТ & $\begin{array}{l}\text { Рост удельного веса занятых в ИКТ отражает переход различных } \\
\text { отраслей в цифровое пространство }\end{array}$ \\
\hline $\begin{array}{l}\text { Уровень инновационной актив- } \\
\text { ности организаций }\end{array}$ & $\begin{array}{l}\text { Данный показатель имеет различные методики формирования, } \\
\text { но в целом отражает уровень наукоемкости региона, его потенциал } \\
\text { в дальнейшем развитии в соответствии с НТП }\end{array}$ \\
\hline $\begin{array}{l}\text { Коэффициент изобретательской } \\
\text { активности (число отечествен- } \\
\text { ных патентных заявок на изобре- } \\
\text { тения, поданных в России) }\end{array}$ & $\begin{array}{l}\text { Отражает восприятие людьми нововведений и их способность на ос- } \\
\text { нове уже имеющихся результатов НТП стимулировать дальнейшее } \\
\text { развитие региона }\end{array}$ \\
\hline $\begin{array}{l}\text { Затраты на инновационную дея- } \\
\text { тельность организаций }\end{array}$ & $\begin{array}{l}\text { Отражает готовность организаций развиваться интенсивным путем } \\
\text { за счет внедрения новых более эффективных изобретений }\end{array}$ \\
\hline
\end{tabular}


Продолжение табл. 1

Continuation of Table 1

\begin{tabular}{|c|c|}
\hline 1 & 2 \\
\hline $\begin{array}{l}\text { Удельный вес затрат на иннова- } \\
\text { ционную деятельность в общем } \\
\text { объеме отгруженных товаров, } \\
\text { выполненных работ, услуг }\end{array}$ & $\begin{array}{l}\text { Рост данного показателя позволяет контролировать внедрение ре- } \\
\text { зультатов НТП в производственную сферу }\end{array}$ \\
\hline $\begin{array}{l}\text { Затраты на разработку и приоб- } \\
\text { ретение программ для ЭВМ и баз } \\
\text { данных, связанных с инноваци- } \\
\text { онной деятельностью }\end{array}$ & $\begin{array}{l}\text { Переход к наукоемким технологиям требует такого же подхода к ин- } \\
\text { струментам, обеспечивающим хранение данных, увеличение затрат }\end{array}$ \\
\hline $\begin{array}{l}\text { Уровень цифровизации местной } \\
\text { телефонной сети }\end{array}$ & $\begin{array}{l}\text { Переход к концепции «умный город» требует перехода средств ком- } \\
\text { муникации к цифровым технологиям }\end{array}$ \\
\hline $\begin{array}{l}\text { Доля организаций, использую- } \\
\text { щих широкополосный доступ } \\
\text { к Интернету }\end{array}$ & $\begin{array}{l}\text { Поскольку Интернет становится новой площадкой для ведения эко- } \\
\text { номической деятельности, увеличение доли организаций свидетель- } \\
\text { ствует о расширяющемся перечне организаций, входящих в цифро- } \\
\text { вое пространство }\end{array}$ \\
\hline $\begin{array}{l}\text { Удельный вес организаций, осу- } \\
\text { ществлявших технологические } \\
\text { инновации }\end{array}$ & $\begin{array}{l}\text { Данный показатель отражает переход организаций к производству } \\
\text { инноваций в технологическом направлении, что также является } \\
\text { критерием перехода региона к категории «умный» }\end{array}$ \\
\hline $\begin{array}{l}\text { Удельный вес инновационных } \\
\text { товаров, работ, услуг в общем } \\
\text { объеме отгруженных товаров, } \\
\text { работ }\end{array}$ & $\begin{array}{l}\text { Положительная динамика данного показателя, так же как и преды- } \\
\text { дущего показателя, свидетельствует об активном переходе региона } \\
\text { в цифровое пространство }\end{array}$ \\
\hline $\begin{array}{l}\text { Обеспеченность населения тор- } \\
\text { говыми площадями современных } \\
\text { форматов на } 1000 \text { человек насе- } \\
\text { ления }\end{array}$ & $\begin{array}{l}\text { Данный показатель является обратным, поскольку его снижение } \\
\text { свидетельствует об отсутствии спроса на физическое пространство } \\
\text { для торговли и переход данной сферы в формат онлайн }\end{array}$ \\
\hline $\begin{array}{l}\text { Доля продаж через Интернет } \\
\text { в общем объеме оборота рознич- } \\
\text { ной торговли }\end{array}$ & $\begin{array}{l}\text { Показатель, обратный предыдущему. Рост доли продаж через Ин- } \\
\text { тернет свидетельствует о переходе сферы торговли к новым формам } \\
\text { ведения деятельности }\end{array}$ \\
\hline $\begin{array}{l}\text { Численность персонала, заня- } \\
\text { того научными исследованиями } \\
\text { и разработками }\end{array}$ & $\begin{array}{l}\text { Количество персонала занятого НИР позволяет определить вовле- } \\
\text { ченность региона в наукоемкое развитие }\end{array}$ \\
\hline $\begin{array}{l}\text { Удельный вес организаций, ис- } \\
\text { пользовавших информационные } \\
\text { и коммуникационные техноло- } \\
\text { гии }\end{array}$ & $\begin{array}{l}\text { Переход организаций к электронному взаимодействию также явля- } \\
\text { ется одним из критериев активного перехода региона к повсеместно- } \\
\text { му внедрению «умных технологий» }\end{array}$ \\
\hline $\begin{array}{l}\text { Удельный вес организаций, ис- } \\
\text { пользовавших Интернет со ско- } \\
\text { ростью не менее } 2 \text { Мб/с }\end{array}$ & $\begin{array}{l}\text { Повышение скорости Интернета свидетельствует об увеличении } \\
\text { объемов информации, а также о применении новых программных } \\
\text { продуктов обработки данных }\end{array}$ \\
\hline $\begin{array}{l}\text { Удельный вес организаций, ис- } \\
\text { пользовавших специальные про- } \\
\text { граммные средства }\end{array}$ & $\begin{array}{l}\text { Рост числа организаций, использующих программные средства, } \\
\text { имеющие узкую специализацию, свидетельствует об освоении но- } \\
\text { вых сфер деятельности в области обработки, анализа и использова- } \\
\text { ния данных, что является неотъемлемой частью концепции «умный } \\
\text { город» }\end{array}$ \\
\hline $\begin{array}{l}\text { Доля населения, использующе- } \\
\text { го сеть Интернет для получения } \\
\text { государственных и муниципаль- } \\
\text { ных услуг }\end{array}$ & $\begin{array}{l}\text { Активное вовлечение населения в сферу G2C и в деятельность элек- } \\
\text { тронного правительства соответствует современным трендам циф- } \\
\text { ровизации и важной частью концепции «умного» города }\end{array}$ \\
\hline
\end{tabular}

Источник: составлено авторами. 
показатели отражают уровень проникновения цифровых технологий в различные сферы экономики, а также восприимчивость людей к этим технологиям, возможности применения новых средств и способов ведения деятельности, обеспеченность «умным» инструментарием, без которого невозможен переход к концепции «умный город». Данные показатели могут выступать контрольными узлами в когнитивной карте перехода региона или города из категории «устойчивый» в категорию «умный».

Таким образом, уровень этих показателей позволяет делать выводы о том, насколько регион или город потенциально готов перейти в категорию «умный», а также отражает эффективность и темпы самого перехода.

Управление развитием «умного города» может осуществляться за счет воздействия на ключевые точки - показатели, наиболее тесно связанные с показателями «умного города». В настоящем исследовании в качестве ключевых точек были определены показатели устойчивого города, поскольку только устойчиво развивающееся территориальное образование сможет накопить и использовать потенциал для перехода в категорию «умный», именно стабильное функционирование и развитие смогут обеспечить эффективный переход. Были выбраны следующие показатели:

- среднедушевые денежные доходы;

- ВРП на душу населения в текущих основных ценах;

- индекс потребительских цен;

- уровень занятости населения в возрасте 15-72 лет;

- уровень безработицы;

- численность студентов в высших учебных организациях на 10000 человек населения;

- число семей (включая одиноких), получивших жилые помещения и улучшивших жилищные условия;

- среднемесячный размер социальной поддержки на одного пользователя;

- численность населения с денежными доходами ниже величины прожиточного минимума;
- индекс производительности труда;

- степень износа основных фондов организаций.

Для целей построения когнитивной карты были проанализированы количественные значения вышеперечисленных показателей за 2016 и 2019 годы. В рамках исследования был проведен корреляционнорегрессионный анализ показателей умного и устойчивого города для выявления зависимости между ними.

Анализ проводился с применением линейного коэффициента корреляции:

$$
I=\frac{\sum x y-\frac{\sum x \cdot \sum y}{n}}{\sqrt{\left[\sum x^{2}-\frac{\left(\sum x\right)^{2}}{n}\right] \cdot\left[\sum y^{2}-\frac{\left(\sum y\right)^{2}}{n}\right]}}
$$

Линейный коэффициент корреляции может принимать значения в пределах от -1 до +1 или по модулю от 0 до 1 . Чем ближе он по абсолютной величине к 1 , тем теснее связь. Знак указывает направление связи: «+»- прямая зависимость, «-» имеет место при обратной зависимости.

\section{Корреляционная матрица связей между показателями умного и устойчивого города}

Расчет корреляции между показателями умного города за 2016 год представлен на рис. 1. Значение показателя $\mathrm{r}$ в интервале $(0: 0,1)$ свидетельствует об отсутствии связи между показателями, в интервале $(0,1: 0,3)$ - слабая связь; $(0,3: 0,5)$ - умеренная; $(0,5: 0,7)$ - заметная; $(0,7: 0,9)$ - близкая связь; $(0,9: 0,99)$ - сильная; $(0,99: 1)$ - функциональная. Исходя из приведенных категорий оценок, анализируя рис. 1, можно сделать вывод, что присутствует наличие сильной связи между показателями инвестиций в интеллектуальную собственность и коэффициентом изобретательской активности, а также между уровнем инновационной активности и удельным весом организаций, использовавших специальные программные средства.

Заметную обратную связь имеют показатели: объем инвестиций в основной 
Olga E. Akimova, Sergey K. Volkov... Transition to the Concept of «Smart City» in the Regions of the Southern Federal...

\begin{tabular}{|c|c|c|c|c|c|c|c|c|c|c|c|c|c|c|}
\hline & $\mathrm{y} 1$ & y2 & y3 & $\mathrm{y}_{4}$ & y5 & $\mathrm{y} 6$ & $\mathrm{y} 7$ & y8 & y9 & $\mathrm{y} 10$ & У11 & $\mathrm{y} 12$ & $\mathrm{y} 13$ & У14 \\
\hline y1 & 1 & & & & & & & & & & & & & \\
\hline y2 & 0,676 & 1 & & & & & & & & & & & & \\
\hline $\mathrm{y}_{3}$ & 0,518 & 0,501 & 1 & & & & & & & & & & & \\
\hline $\mathrm{y} 4$ & 0,037 & $-0,284$ & $-0,535$ & 1 & & & & & & & & & & \\
\hline y5 & 0,782 & 0,201 & \begin{tabular}{l|l}
0,458 \\
\end{tabular} & 0,338 & 1 & & & & & & & & & \\
\hline У6 & 0,507 & 0,203 & $-0,370$ & 0,582 & 0,432 & 1 & & & & & & & & \\
\hline y7 & 0,162 & $-0,490$ & $-0,075$ & 0,569 & 0,688 & 0,380 & 1 & & & & & & & \\
\hline y8 & 0,077 & 0,584 & 0,125 & 0,412 & 0,617 & 0,045 & 0,816 & 1 & & & & & & \\
\hline y9 & $-0,536$ & $-0,035$ & $-0,593$ & 0,197 & 0,760 & $-0,103$ & 0,620 & 0,528 & 1 & & & & & \\
\hline $\mathrm{Y} 10$ & 0,024 & $-0,286$ & $-0,580$ & 0,979 & 0,304 & 0,673 & 0,560 & 0,394 & 0,200 & 1 & & & & \\
\hline У11 & 0,708 & 0,161 & 0,201 & 0,407 & 0,692 & 0,362 & 0,380 & 0,379 & $-0,316$ & 0,312 & 1 & & & \\
\hline $\mathrm{y} 12$ & 0,359 & 0,104 & $-0,518$ & 0,756 & 0,384 & 0,788 & 0,374 & 0,043 & 0,077 & 0,745 & 0,423 & 1 & & \\
\hline $\mathrm{y} 13$ & $-0,172$ & 0,092 & $-0,285$ & 0,284 & $-0,092$ & 0,316 & $-0,055$ & $-0,075$ & 0,293 & 0,398 & $-0,530$ & 0,286 & 1 & \\
\hline У14 & 0,604 & $-0,074$ & 0,659 & 0,174 & 0,807 & $-0,064$ & $-0,597$ & $-0,554$ & 0,984 & 0,201 & $-0,450$ & 0,085 & 0,394 & 1 \\
\hline
\end{tabular}

Уn - соответствующий показатель «умного города» из табл. 1.

Источник: составлено авторами.

Рис. 1. Корреляционная матрица связей между показателями умного города за 2016 год

Fig. 1. Correlation matrix of links between smart city indicators for 2016

капитал, направленных на приобретение ИКТ, уровень инновационной активности организаций, а также показатель объема инвестиций в ИКТ организациями, использовавшими специальные программные средства. Поскольку данные показатели имеют обратную связь, то увеличение объема инвестиций в ИКТ вызовет снижение инновационной активности и снижение доли предприятий, использовавших специальные программные средства. Данный факт необходимо учитывать при формировании когнитивной карты. Ряд показателей имеет слабую связь. Например, показатель «число самостоятельных образовательных организаций высшего образования, использующих дистанционные образовательные технологии для реализации образовательных программ высшего образования» слабо связан с показателями: «прирост высокопроизводительных рабочих мест; удельный вес занятых в ИКТ»; «коэффициент изобретательской активности (число отечественных патентных заявок на изобретения, поданных в России)»; «затраты на разработку и приобретение программ для ЭВМ и баз данных, связанных с инновационной деятельностью». Показатель «количество персональных компьютеров в образовательных организациях» имеет очень слабую связь либо совсем ее не имеет со всеми выделенными показателями. Исключением являются: показатель «затраты на исследования и разработки в\% к ВВП в целом по России», с которым имеется заметная прямая связь, показатель «удельный вес занятых в ИКТ», с которым наблюдается заметная обратная связь.

Таким образом, показатели, имеющие заметную и сильную связь, будут выстроены в цепочки в когнитивной карте; показатели, не имеющие или имеющие слабую связь, будут формировать отдельные направления развития.

В целом, проанализированные связи являются устойчивыми. Хотя корреляционная матрица для показателей «умного города» в 2019 году, аналогичная отраженной на рис. 1, свидетельствует об определенном ослаблении связанности внутри данной системы (что может отражать определенные проблемы с обеспечением системности развития «умных городов» в России), однако теснота большей части выявленных связей существенно не изменилась.

Анализ взаимосвязи и взаимозависимости показателей устойчивого города показал следующие результаты (рис. 2).

Как видно из данных рис. 2, показатели устойчивого города не имеют между 
Olga E. Akimova, Sergey K. Volkov... Transition to the Concept of «Smart City» in the Regions of the Southern Federal...

\begin{tabular}{|c|c|c|c|c|c|c|c|c|c|c|c|}
\hline & P1 & P2 & P3 & P4 & P5 & P6 & P7 & P8 & P9 & P10 & P11 \\
\hline P1 & $\mathbf{1}$ & & & & & & & & & & \\
\hline P2 & 0,574 & $\mathbf{1}$ & & & & & & & & & \\
\hline P3 & $-0,054$ & 0,550 & $\mathbf{1}$ & & & & & & & & \\
\hline P4 & 0,200 & $\mathbf{0}, 752$ & $-0,333$ & $\mathbf{1}$ & & & & & & & \\
\hline P5 & $-0,556$ & $-0,093$ & $-0,097$ & 0,147 & $\mathbf{1}$ & & & & & & \\
\hline P6 & $-0,355$ & $-0,173$ & $-0,394$ & 0,248 & 0,248 & $\mathbf{1}$ & & & & & \\
\hline P7 & 0,597 & 0,663 & $-0,159$ & 0,619 & $-0,579$ & $-0,064$ & $\mathbf{1}$ & & & & \\
\hline P8 & 0,347 & 0,770 & $-0,695$ & 0,613 & $-0,125$ & 0,185 & 0,733 & $\mathbf{1}$ & & & \\
\hline P9 & $-0,834$ & $-0,341$ & 0,189 & 0,035 & 0,623 & 0,220 & $-0,311$ & $-0,102$ & $\mathbf{1}$ & & \\
\hline P10 & 0,781 & 0,283 & $-0,145$ & 0,056 & 0,718 & $-0,047$ & 0,639 & 0,401 & $-0,785$ & $\mathbf{1}$ & \\
\hline P11 & $-0,311$ & $0,0,799$ & 0,717 & $-0,576$ & 0,006 & $-0,191$ & $-0,453$ & 0,763 & 0,121 & $-0,055$ & $\mathbf{1}$ \\
\hline
\end{tabular}

Источник: составлено авторами.

Рис. 2. Корреляционная матрица связей между показателями устойчивого города за 2016 год

Fig. 2. Correlation matrix of links between sustainable city indicators for 2016

собой сильной зависимости, наблюдается только заметная зависимость между такими показателями, как «среднедушевые денежные доходы» и «индекс производительности труда», а «численность населения с денежными доходами ниже величины прожиточного минимума» имеет обратную зависимость, т. е. чем выше среднедушевые доходы, тем ниже численность населения с денежными доходами ниже величины прожиточного минимума; «ВРП на душу населения в текущих основных ценах» имеет значимую связь с показателями «уровень занятости населения в возрасте 15-72 лет» и «среднемесячный размер социальной поддержки на одного пользователя», т. е. рост ВРП на душу населения вызовет рост размера среднемесячной социальной поддержки. Также выявлено наличие значимой обратной связи с показателем «степень износа основных фондов организаций».

Показатель «численность студентов в высших учебных организациях на 10000 человек населения» не имеет связи либо имеет слабую связь со всеми остальными показателями, следовательно, при построении когнитивной карты данный показатель будет использоваться обособленно. Остальные показатели, имеющие значимую и заметную связь, будут объединяться в группы, в которых один показатель является ключевым, посредством него осуществляется управление показателями-узлами, а остальные - инструментами управления ключевым показателем.

Для определения ключевого показателя была рассчитана корреляция между индикаторами умного и устойчивого города (рис. 3).

\section{Результаты}

Исходя из приведенных расчетов, можно сделать следующие выводы.

1. На показатель «затраты на исследования и разработки в\% к ВВП в целом по России» значимое и умеренное влияние оказывают два показателя: «индекс производительности труда», с которым имеется прямая зависимость, «уровень безработицы» - обратная.

2. На показатель «доля высокотехнологичных и наукоемких отраслей экономики в ВРП» значимое прямое влияние оказывают следующие показатели: «индекс потребительских цен» и «степень износа основных фондов организаций». Также существует обратная связь с показателем «уровень безработицы».

3. На показатель «прирост высокопроизводительных рабочих мест» прямое значимое влияние оказывают показатели: «индекс потребительских цен» и «степень износа основных фондов организаций»; обратное значимое влияние оказывают показатели «ВРП на душу населения в текущих основных ценах» и «среднемесячный размер социальной поддержки на одного пользователя». 
Olga E. Akimova, Sergey K. Volkov... Transition to the Concept of «Smart City» in the Regions of the Southern Federal...

\begin{tabular}{|c|c|c|c|c|c|c|c|c|c|c|c|c|c|c|}
\hline & y1 & y2 & y3 & y4 & y5 & y6 & y7 & y8 & y9 & y10 & y11 & y12 & y13 & y14 \\
\hline P1 & 0,301 & $-0,041$ & $-0,158$ & 0,764 & 0,536 & 0,301 & 0,510 & 0,347 & $-0,050$ & 0,630 & 0,681 & 0,704 & $-0,133$ & $-0,133$ \\
\hline P2 & $-0,228$ & $-0,470$ & 0,725 & 0,888 & 0,147 & 0,543 & 0,612 & 0,339 & 0,170 & 0,902 & 0,052 & 0,726 & 0,424 & 0,225 \\
\hline P3 & 0,262 & 0,643 & 0,659 & $-0,447$ & 0,084 & $-0,452$ & $-0,482$ & $-0,289$ & $-0,047$ & $-0,516$ & $-0,122$ & $-0,247$ & 0,154 & $-0,090$ \\
\hline P4 & 0,033 & $-0,280$ & $-0,389$ & 0,594 & 0,379 & 0,633 & 0,625 & 0,462 & $-0,194$ & 0,696 & $-0,099$ & 0,569 & 0,699 & $-0,092$ \\
\hline P5 & $-0,530$ & $-0,519$ & $-0,132$ & $-0,488$ & $-0,348$ & $-0,388$ & 0,043 & 0,097 & $-0,207$ & $-0,430$ & $-0,644$ & $-0,389$ & 0,078 & $-0,085$ \\
\hline P6 & 0,267 & $-0,263$ & 0,165 & $-0,129$ & 0,332 & 0,231 & 0,325 & 0,543 & $-0,484$ & $-0,025$ & 0,226 & $-0,196$ & $-0,136$ & $-0,475$ \\
\hline P7 & 0,381 & 0,180 & $-0,404$ & 0,818 & 0,394 & 0,790 & 0,267 & 0,128 & 0,213 & 0,843 & 0,405 & 0,875 & 0,500 & 0,197 \\
\hline P8 & $-0,054$ & $-0,366$ & $-0,833$ & 0,740 & 0,022 & 0,717 & 0,332 & 0,179 & 0,315 & 0,802 & 0,213 & 0,745 & 0,298 & 0,347 \\
\hline P9 & $-0,415$ & $-0,040$ & $-0,086$ & $-0,557$ & $-0,595$ & $-0,283$ & $-0,563$ & $-0,309$ & 0,291 & $-0,434$ & 0,58 & $-0,446$ & 0,462 & 0,382 \\
\hline P10 & 0,704 & 0,305 & $-0,050$ & 0,560 & 0,609 & 0,608 & 0,327 & 0,114 & $-0,149$ & 0,480 & 0,894 & 0,733 & $-0,307$ & $-0,245$ \\
\hline P11 & 0,434 & 0,753 & 0,702 & 0,770 & 0,042 & $-0,303$ & $-0,506$ & $-0,534$ & $-0,296$ & $-0,807$ & $-0,048$ & $-0,348$ & $-0,269$ & $-0,315$ \\
\hline
\end{tabular}

Источник: составлено авторами.

Рис. 3. Корреляционная матрица связей между показателями умного и устойчивого города за 2016 год

Fig. 3. Correlation matrix of links between indicators of smart and sustainable cities for 2016

4. На показатель «уровень инновационной активности организаций» оказывает значимое влияние показатели: «среднедушевые денежные доходы», «ВРП на душу населения в текущих основных ценах», «уровень занятости населения в возрасте 15-72 лет», «число семей (включая одиноких), получивших жилые помещения и улучшивших жилищные условия», «среднемесячный размер социальной поддержки на одного пользователя», «индекс производительности труда»; обратное значимое влияние оказывают показатели: «численность населения с денежными доходами, ниже величины прожиточного минимума», «степень износа основных фондов организаций»».

5. На показатель «коэффициент изобретательской активности» оказывают значимое прямое влияние: «среднедушевые денежные доходы», «индекс производительности труда»; обратное влияние имеет один показатель - «численность населения с денежными доходами ниже величины прожиточного минимума».

6. На показатель «удельный вес затрат на инновационную деятельность в общем объеме отгруженных товаров, выполненных работ, услуг» прямое значимое влияние оказывают показатели: «ВРП на душу населения в текущих основных ценах», «уровень занятости населения в возрасте
15-72 лет», «число семей (включая одиноких), получивших жилые помещения и улучшивших жилищные условия», «среднемесячный размер социальной поддержки на одного пользователя», «индекс производительности труда». Обратного влияния на данный показатель показатели «устойчивого города» не имеют.

7. На показатель «уровень цифровизации местной телефонной сети (город)» прямое заметное влияние оказывают показатели: «среднедушевые денежные доходы», «ВРП на душу населения в текущих основных ценах», «уровень занятости населения в возрасте 15-72 лет» и обратное заметное влияние оказывают показатели: «численность населения с денежными доходами, ниже величины прожиточного минимума», «степень износа основных фондов организаций».

8. На показатель «уровень цифровизации местной телефонной сети (сельская местность)» прямое заметное влияние оказывает показатель «численность студентов в высших учебных организациях на 10000 человек населения», а обратная заметная зависимость выявлена у показателя «степень износа основных фондов организаций».

9. На показатель «доля организаций, использующих широкополосный доступ к сети Интернет» ни один показатель 
не оказывает заметного влияния, выявлена слабая связь с показателями устойчивого города.

10. На показатель «удельный вес организаций, осуществлявших технологические инновации» оказывают значимое прямое влияние показатели: «среднедушевые денежные доходы», «ВРП на душу населения в текущих основных ценах», «уровень занятости населения в возрасте 15-72 лет», «число семей (включая одиноких), получивших жилые помещения и улучшивших жилищные условия», «среднемесячный размер социальной поддержки на одного пользователя» и обратное значимое влияние оказывает показатель «степень износа основных фондов организаций».

11. На показатель «удельный вес инновационных товаров, работ, услуг в общем объеме отгруженных товаров, работ» оказывает прямое влияние показатель «индекс производительности труда», а обратная значимая зависимость выявлена с показателем «численность населения с денежными доходами ниже величины прожиточного минимума».

12. На показатель «доля продаж через Интернет в общем объеме оборота розничной торговли» прямое значимое влияние оказывают показатели: «среднедушевые денежные доходы», «ВРП на душу населения в текущих основных ценах», «число семей (включая одиноких), получивших жилые помещения и улучшивших жилищные условия», «среднемесячный размер социальной поддержки на одного пользователя» «индекс производительности труда». Показателей, имеющих обратную видимую или значимую связь с данным показателем, не выявлено.

13. На показатель «удельный вес организаций, использовавших информационные и коммуникационные технологии», значимое влияние оказывает только один показатель - «уровень занятости населения в возрасте 15-72 лет»; показателей, имеющих обратную заметную или значимую связь, не выявлено.

14. На показатель «удельный вес организаций, использовавших Интернет со скоростью не менее 2 Мб/с» ни один из выделенных показателей устойчивого города влияния не оказывает.

Для исследования динамики развития концепции «умный город» был проведен корреляционно-регрессионный анализ выделенных показателей за 2019 год (рис. 4).

Сравнительный анализ корреляционных матриц на рис. 3 и 4 выявил тенденцию к ослаблению зависимости показателей «умного города» от показателей «устойчивого города», что свидетельствует о постепенном переходе территориального образования к концепции «умный город» и постепенного проникновения результатов

\begin{tabular}{|c|c|c|c|c|c|c|c|c|c|c|c|c|c|c|}
\hline & y1 & $\mathrm{y}_{2}$ & y3 & y4 & y5 & y6 & y7 & y8 & y9 & Y10 & y11 & У12 & У13 & Y14 \\
\hline $\mathrm{P} 1$ & 0,399 & 0,111 & 0,201 & 0,382 & 0,189 & 0,446 & 0,541 & 0,300 & 0,366 & 0,428 & 0,423 & 0,290 & $-0,082$ & 0,506 \\
\hline P2 & $-0,180$ & 0,671 & 0,594 & 0,221 & 0,348 & $-0,098$ & 0,722 & 0,555 & 0,048 & $-0,120$ & $-0,378$ & $-0,350$ & 0,385 & 0,582 \\
\hline P3 & $-0,127$ & $-0,059$ & 0,204 & $-0,179$ & 0,528 & $-0,159$ & $-0,080$ & 0,069 & 0,609 & $-0,339$ & $-0,575$ & $-0,302$ & 0,520 & $-0,386$ \\
\hline $\mathrm{P} 4$ & 0,499 & $-0,041$ & 0,066 & 0,295 & 0,592 & 0,560 & 0,423 & 0,378 & $-0,179$ & 0,421 & $-0,524$ & 0,363 & 0,853 & 0,367 \\
\hline P5 & 0,557 & $-0,412$ & 0,350 & 0,735 & $-0,126$ & $-0,450$ & $-0,159$ & 0,242 & $-0,259$ & $-0,608$ & $-0,170$ & $-0,261$ & $-0,055$ & $-0,490$ \\
\hline P6 & 0,256 & $-0,456$ & $-0,067$ & 0,282 & 0,205 & 0,340 & 0,305 & 0,501 & 0,366 & 0,350 & 0,435 & $-0,007$ & $-0,221$ & 0,134 \\
\hline $\mathrm{P} 7$ & 0,601 & 0,548 & $-0,223$ & 0,899 & 0,452 & 0,399 & $-0,072$ & $-0,227$ & 0,217 & 0,483 & $-0,046$ & $-0,181$ & 0,287 & 0,450 \\
\hline P8 & $-0,210$ & $-0,056$ & 0,574 & 0,311 & 0,486 & $-0,326$ & 0,201 & 0,089 & $-0,118$ & $-0,370$ & $-0,338$ & 0,783 & 0,263 & 0,251 \\
\hline P9 & $-0,295$ & 0,054 & $-0,032$ & $-0,396$ & $-0,197$ & $-0,336$ & $-0,683$ & $-0,150$ & $-0,098$ & $-0,404$ & $-0,379$ & $-0,351$ & 0,149 & $-0,361$ \\
\hline P10 & 0,486 & $-0,027$ & 0,213 & 0,494 & 0,540 & 0,535 & 0,746 & 0,446 & 0,194 & 0,476 & 0,571 & 0,224 & $-0,142$ & 0,325 \\
\hline P11 & $-0,303$ & 0,018 & $-0,394$ & $-0,228$ & $-0,198$ & $-0,390$ & $-0,518$ & $-0,511$ & $-0,462$ & $-0,298$ & $-0,510$ & $-0,148$ & 0,158 & $-0,444$ \\
\hline
\end{tabular}

Источник: составлено авторами.

Рис. 4. Корреляционная матрица связей между показателями умного и устойчивого города за 2019 год

Fig. 4. Correlation matrix of links between smart and sustainable city indicators for 2019 
НТП и наукоемких технологий в различные сферы жизнедеятельности людей.

\section{Заключение}

Проведенный

корреляционнорегрессионный анализ показателей «устойчивого города» и «умного города» позволил выявить основные показатели, воздействующие на эффективность перехода территориального образования к концепции «умный город», посредством которых будет осуществляться управление этим переходом. Также были выявлены показатели, оказывающие влияние на управляющие показатели и позволяющие контролировать и изменять их уровень за счет оказываемого на них влияния. На основе полученных результатов будет построена когнитивная карта процесса перехода территориального образования к концепции «умный город», индексы системной оценки развития «умного горда» в конкретных регионах.

\section{Список литературы / References}

Ahvenniemi, H., Huovila, A., Pinto-Seppä, I., Airaksinen, M. (2017) What are the differences between sustainable and smart cities?, Cities, 60, 234-245.

Akande, A., Cabral, P., Gomes, P., Casteleyn, S. (2019) The Lisbon ranking for smart sustainable cities in Europe, Sustainable Cities and Society, 44, 475-487.

Akimova, O.E., Volkov, S.K., Kuzlaeva, I.M. (2020) Koncepciya «umnyj ustojchivyj gorod»: Sistema pokazatelej dlya ocenki urovnya regional'noj ustojchivosti I adaptivnosti regional'nogo razvitiya [The concept of «smart sustainable city»: a system of indicators to assess the level of regional sustainability and adaptability of regional development], In Regional'naya ekonomika: teoriya I praktika [Regional Economy: Theory and Practice], 12 (483), 2354-2390.

Albino, V., Berardi, U., Dangelico, R.M. (2015) Smart cities: Definitions, dimensions, performance, and initiatives, Journal of Urban Technology, 22 (1), 3-21.

Anthopoulos, L., Janssen, M., Weerakkody, V. A (2016) Unified Smart City Model (USCM) for smart city conceptualization and benchmarking, International Journal of e-Government Research, 12 (2), 76-92.

Berardi, U. (2015). Sustainability assessments of buildings, communities, and cities, In Assessing and measuring environmental impact and sustainability, 497-545.

Bibri, S. E., Krogstieb, J. (2017) Smart sustainable cities of the future: An extensive interdisciplinary literature review, Sustainable Cities and Society, 31, 183-212.

Bifulco, F., Tregua, M., Amitrano, C., D'Auria, A. (2016) ICT and sustainability in smart cities management, International Journal of Public Sector Management, 29(2), 132-147.

Camagni, R. (1998) Sustainable urban development: definition and reasons for a research programme, International Journal of Environment and Pollution, 10(1), 6-27.

ETSI TS103 463 V1.1.1 (2017-07). Access, Terminals, Transmission and Multiplexing (ATTM); Key Performance Indicators for Sustainable Digital Multiservice Cities (2017). Sophia Antipolis, ETSI, 62 p.

Hamilton, A., Mitchell, G., Yli-Karjanmaa, S. (2002) The BEQUEST toolkit: a decision support system for urban sustainability, Building Research and Information, 30(2), 109-115.

Huovila, A., Bosch, P., Airaksinen, M. (2019) Comparative analysis of standardized indicators for Smart sustainable cities: What indicators and standards to use and when?, Cities, 89, 141-153.

Jovovic, R., Draskovic, M., Delibasic, M., Jovovic, M. (2017) The concept of sustainable regional development - institutional aspects, policies and prospects, Journal of International Studies, 10(1), 255-266.

Kramers, A., Höjer, M., Lövehagen, N., Wangel, J. (2014) Smart sustainable cities: Exploring ICT solutions for reduced energy use in cities, Environmental Modelling \& Software, 56, 52-62.

Mega, V., Pedersen, J. (1998). Urban Sustainability Indicators. European Foundation for the Improvement of Living and Working Conditions, Dublin.

Novikov, I.V. (2016) Rol' MSE v standartizacii umnyx ustojchivyx gorodov [The role of ITU in the standardization of smart sustainable cities], In Vestnik Moskovskogo universiteta imeni S. Yu. Vitte. Seriya 
1: ekonomika I upravlenie [Herald of Moscow Witte University. Series 1: Economics and Management], 3(18), 74-79.

Pearce, D.W., Atkinson, G.D. (1993) Capital theory and the measurement of sustainable development: an indicator of «weak» sustainability, Ecological Economics, 8(2), 103-108.

Poroxin, A.V. (2014) Ustojchivost' kak opredelyayuschaya xarakteristika sostoyaniya social'noekonomicheskoj sistemy [Sustainability as a defining characteristic of the state of the socio-economic system], In Fundamental'nye issledovaniya [Fundamental studies], 12 (4), 816-821.

Poroxina, E.V. (2014) Istochniki I Sistema faktorov, formiruyuschix ekonomicheskuyu ustojchivost' regiona (na primere Kemerovskoj oblasti) [Sources and system of factors that form the economic sustainability of the region (case of Kemerovo region)], In Fundamental'nye issledovaniya [Fundamental studies], $12(3), 596-600$.

Rees, W.E. (1996) Revisiting carrying capacity: area-based indicators of sustainability, Population and Environment: A Journal of Interdisciplinary Studies, 17(3), 195-215.

Rekomendaciya MSE-T Y.4901/L.1601. Klyuchevye pokazateli deyatel'nosti, svyazannye s ispol'zovaniem informacionno-kommunikacionnyh tekhnologij v «umnyh» ustojchivyh gorodah (2018) [ITU-T Recommendation Y.4901 / L.1601. Key performance indicators related to the use of information and communication technologies in smart sustainable cities]. Geneva, MSE, $26 \mathrm{p}$.

Rekomendaciya MSE-T Y.4902/L.1602. Klyuchevye pokazateli deyatel'nosti, svyazannye s vozdejstviem informacionno- kommunikacionny tekhnologij na ustojchivost' "umnyh» ustojchivyh gorodov (2018) [ITU-T Recommendation Y.4902 / L.1602. Key performance indicators related to the impact of information and communications technologies on the resilience of smart sustainable cities]. Geneva, MSE, $22 \mathrm{p}$.

Rekomendaciya MSE-T Y.4903/L.1603. Klyuchevye pokazateli deyatel'nosti «umnyh» ustojchivyh gorodov dlya ocenki dostizheniya celej v oblasti ustojchivogo razvitiya (2018) [ITU-T Recommendation Y.4903 / L.1603. Key Performance Indicators of Smart Sustainable Cities to Measure Achievement of the Sustainable Development Goals]. Geneva, MSE, 58 p.

Sharifi, A., Murayama, A. (2013) A critical review of seven selected neighborhood sustainability assessment tools, Environmental Impact Assessment Review, 38, 73-87.

Shen, L-Y., Jorge Ochoa, J., Shah, M.N., Zhang, X. (2011) The application of urban sustainability indicators - a comparison between various practices, Habitat International, 35(1), 17-29.

Starikova, M.S., Bezuglyi, E.A., Shakhov, V.V. (2018) Kreativnyj potencial kak osnova innovacionnogo razvitiya regiona [Creative potential as the basis for innovative development of the region], In Voprosy innovacionnoj ekonomiki [Russian Journal of Innovation Economics], 2, 235-254. 